\title{
Synthesis, characterization, controlled release, and antibacterial studies of a novel streptomycin chitosan magnetic nanoantibiotic
}

This article was published in the following Dove Press journal:

International Journal of Nanomedicine

16 January 2014

Number of times this article has been viewed

\begin{abstract}
Samer Hasan Hussein-Al-Ali'
Mohamed Ezzat El

Zowalaty ${ }^{2,6}$

Mohd Zobir Hussein ${ }^{3}$

Maznah Ismail',4

Thomas J Webster ${ }^{5,7}$

'Laboratory of Molecular Biomedicine, ${ }^{2}$ Laboratory of Vaccines and Immunotherapeutics, Institute of Bioscience, ${ }^{3}$ Materials Synthesis and Characterization Laboratory, Institute of Advanced Technology, ${ }^{4}$ Department of Nutrition and Dietetics, Faculty of Medicine and Health Science, Universiti Putra Malaysia, Selangor, Malaysia; ${ }^{5}$ Department of Chemical Engineering and Program in Bioengineering, Northeastern University, Boston, MA, USA; ${ }^{6}$ Department of Environmental Health, Faculty of Public Health and Tropical Medicine, Jazan University, Jazan, ${ }^{7}$ Center of Excellence for Advanced Materials Research, King Abdulaziz University, Jeddah, Saudi Arabia
\end{abstract}

Correspondence: Mohd Zobir Hussein Materials Synthesis and Characterization Laboratory, Institute of Advanced Technology, Universiti Putra Malaysia, Serdang, Selangor 43400, Malaysia $\mathrm{Tel}+6038946680 \mathrm{I}$

Fax +60 389435380

Email mzobir@upm.edu.my

\begin{abstract}
This study describes the preparation, characterization, and controlled release of a streptomycin-chitosan-magnetic nanoparticle-based antibiotic in an effort to improve the treatment of bacterial infections. Specifically, chitosan-magnetic nanoparticles were synthesized by an incorporation method and were characterized by Fourier transform infrared spectroscopy, X-ray diffraction, thermogravimetric analysis, and vibrating sample magnetometry. Streptomycin was incorporated into the nanoparticles to form a streptomycin-coated chitosan-magnetic nanoparticle (Strep-CS-MNP) nanocomposite. The release profiles showed an initially fast release, which became slower as time progressed. The percentage of drug released after 350 minutes was around $100 \%$, and the best fit mathematical model for drug release was the pseudo-second order model. The Strep-CS-MNP nanocomposite showed enhanced antibacterial activity against methicillinresistant Staphylococcus aureus. This study forms a significant basis for further investigation of the Strep-CS-MNP nanocomposite in the treatment of various bacterial infections.
\end{abstract}

Keywords: magnetic nanoparticles, streptomycin, nanoantibiotics, chitosan, release, antimicrobial activity, methicillin-resistant Staphylococcus aureus

\section{Introduction}

Magnetic iron oxide nanoparticles with superparamagnetic properties and modified surfaces have been tested in various in vivo applications, including magnetic resonance imaging, tissue repair, immunoassays, detoxification, hyperthermia, and drug delivery. ${ }^{1,2}$ Magnetic iron oxide nanoparticles with high magnetization, small particle size, and a narrow particle size distribution are very important in the biomedical and bioengineering fields for achieving uniform physical and chemical properties. ${ }^{3}$ Iron oxide nanoparticles with small particle sizes have been shown to have antimicrobial properties $^{4}$ that depend on three factors, ie, size, stability, and concentration in the growth medium. However, magnetic iron oxide nanoparticles suffer from agglomeration during preparation, which decreases their efficacy in terms of inhibiting bacterial growth. Therefore, such particle surfaces need to be coated with nontoxic and biocompatible polymers to avoid agglomeration. Chitosan has been widely used as a nanoparticle coating material because it is nontoxic, biodegradable, biocompatible, and has intrinsic antimicrobial properties. ${ }^{5,6}$ Furthermore, silver nanoparticles, including silver-coated magnetic nanoparticles, were recently developed as promising antimicrobial magnetic based-nanoparticles. ${ }^{7,8}$

Streptomycin is the oldest broad-spectrum antibiotic used in the treatment of bacterial infections, including in tuberculosis, a fatal infection in humans and caused by Mycobacterium tuberculosis. ${ }^{9,10}$ Streptomycin is the prototype aminoglycoside antibiotic

submit your manuscript | www.dovepress.com 
and has been used in the clinic since the 1940s. ${ }^{11}$ Streptomycin exerts its bactericidal action by binding to the 16S rRNA of the $30 \mathrm{~S}$ subunit of the bacterial ribosome, thereby preventing protein synthesis through a complex pathway. ${ }^{12}$

Streptomycin was widely used until widespread emergence of bacterial resistance limited its clinical usefulness. The mechanism of microbial resistance to streptomycin has been reviewed extensively elsewhere. ${ }^{12}$ Several efforts were made to restore the usefulness of streptomycin and other aminoglycosides by chemical modification to develop new generations of aminoglycosides that bypass existing multidrug bacterial resistance pathways and reduce the concerns about their toxicity, in particular ototoxicity and nephrotoxicity. ${ }^{13}$ Despite their limitations, including bacterial resistance, poor oral pharmacokinetics, clinical toxicity, and side effects, aminoglycosides (including the prototype streptomycin) remain clinically significant antimicrobial agents in the treatment of a broad range of bacterial infections. ${ }^{13,14}$

In the present study, for the first time, we report on novel streptomycin-loaded chitosan-magnetic iron oxide nanoparticles (Strep-CS-MNP) and investigate their controlled release and antimicrobial activity in vitro. The latter was determined using a pathogenic strain of methicillin-resistant Staphylococcus aureus (MRSA), a microorganism causing serious infection and of considerable public health and clinical significance.

\section{Materials and methods \\ Materials}

Ferric chloride hexahydrate $\left(\mathrm{FeCl}_{3} \cdot 6 \mathrm{H}_{2} \mathrm{O}\right)(99 \%)$ and ferrous chloride tetrahydrate $\left(\mathrm{FeCl}_{2} \cdot 4 \mathrm{H}_{2} \mathrm{O}\right)(>99 \%)$ were obtained from Merck KGaA (Darmstadt, Germany). Chitosan (low molecular weight, deacetylation $75 \%-85 \%$ ) was purchased from Sigma-Aldrich (Saint Louis, MO, USA). Acetic acid (99.8\%) was sourced from Hamburg Industries Inc (Hamburg, Germany). Streptomycin sulfate was obtained from Sigma-Aldrich. All aqueous solutions were prepared with deionized water.

\section{Preparation of iron oxide nanoparticles}

$\mathrm{FeCl}_{3} \cdot 6 \mathrm{H}_{2} \mathrm{O}(0.3 \mathrm{Mol})$ and $\mathrm{FeCl}_{2} \cdot 4 \mathrm{H}_{2} \mathrm{O}(0.15 \mathrm{Mol})$ were dissolved in $50 \mathrm{~mL}$ of water. The mixture of $\mathrm{Fe}^{3+}$ and $\mathrm{Fe}^{2+}$ in solution was added slowly to a $2 \mathrm{M} \mathrm{NaOH}$ solution while stirring, with the $\mathrm{pH}$ kept at less than 10 at room temperature. The solution was sonicated for a further 60 minutes at room temperature. The particles were filtered, washed three times with deionized water, and dried.

\section{Preparation of CS-MNP}

Chitosan $(2.0 \mathrm{~g})$ was dissolved in a $1 \%$ acetic acid solution. The chitosan solution and $\mathrm{Fe}_{3} \mathrm{O}_{4}$ were mixed together in a flask, and the mixture was stirred for 18 hours. Chitosan-coated magnetic nanoparticles (CS-MNP) were separated using a permanent magnet and dried at $70^{\circ} \mathrm{C}$ for 2 hours.

\section{Preparation of Strep-CS-MNP}

Streptomycin was loaded onto CS-MNP using a method similar to that reported previously. ${ }^{15}$ Briefly, a streptomycin solution $(0.58 \mathrm{~g})$ was added dropwise while stirring into an aqueous dispersion of MNP. The mixture of CS-MNP in the streptomycin solution was magnetically stirred at room temperature for 18 hours to facilitate streptomycin uptake. The product, ie, Strep-CS-MNP, was separated using a permanent magnet.

\section{Loading and release of streptomycin from Strep-CS-MNP}

To measure the amount of streptomycin loaded on the CS-MNP, $5 \mathrm{mg}$ of the nanocomposite was weighed accurately and dissolved in concentrated $\mathrm{HCl} / \mathrm{HNO}_{3}$, ie, conditions that would completely dissolve this nanocomposite and release $100 \%$ of the streptomycin content. Next, the amount of streptomycin released was measured by ultraviolet-visible spectroscopy using streptomycin absorbance at $200 \mathrm{~nm}$ and calibration curves.

In order to determine the percentage release and drug release kinetics, $85 \mathrm{mg}$ of each nanocomposite was suspended into $250 \mathrm{~mL}$ of phosphate-buffered saline at $\mathrm{pH}$ 7.4. A quantity of medium solution $(3 \mathrm{~mL})$ was removed for analysis at given time intervals and replaced with $3 \mathrm{~mL}$ of the same buffered solution. The cumulative amount of streptomycin released into the solution was measured at different time intervals using an ultraviolet-visible spectrophotometer at $200 \mathrm{~nm}$.

\section{Characterization of Strep-CS-MNP nanocomposite}

The magnetic nanoparticles and nanocomposite were characterized by Fourier transform infrared (FTIR) spectroscopy, X-ray diffraction, thermogravimetric analysis, and magnetization measurements. The FTIR spectra were recorded over the range of $400-4,000 \mathrm{~cm}^{-1}$ on a Thermo Nicolet Nexus, Smart Orbit spectrometer using the $\mathrm{KBr}$ disk method. X-ray diffraction spectra were obtained in the range of 20-70 degrees using an XRD-6000 diffractometer 
(Shimadzu, Tokyo, Japan) with $\mathrm{CuK}_{\alpha}$ radiation $(\lambda 1.5406 \AA$ ) at $30 \mathrm{kV}$ and $30 \mathrm{~mA}$. Thermogravimetric analysis was carried out using a Metter-Toledo 851e instrument (Greifensee, Switzerland) with a heating rate of $10^{\circ} \mathrm{C}$ per minute in $150 \mu \mathrm{L}$ alumina crucibles and in the range of $30^{\circ} \mathrm{C}-900^{\circ} \mathrm{C}$. A scanning electron microscope (Nova ${ }^{\mathrm{TM}}$ NanoSEM 230; FEI, Hillsboro, OR, USA) was used to observe the surface morphology of the samples. Magnetic properties were evaluated using a 7404 vibrating sample magnetometer Lake Shore Cryotronics Inc (Westerville, OH, USA). Ultravioletvisible spectra were measured to determine the controlled release which was performed using an ultraviolet-visible spectrophotometer (Perkin Elmer, Waltham, MA, USA).

\section{Antimicrobial activity of Strep-CS-MNP against MRSA}

A bacterial strain of methicillin-resistant Staphylococcus aureus (MRSA), a human pathogen of clinical significance and causing a range of minor to life-threatening infections of the skin, respiratory tract, and urinary tract, as well as septicemia, was obtained from the Microbial Culture Collection Unit, Institute of Bioscience, Universiti Putra Malaysia for use in the present study. MRSA cultures were maintained on Luria-Bertani agar (Fluka, Buchs, Switzerland). Prior to incubation with the novel nanoparticles, the bacteria were cultured overnight in $5 \mathrm{~mL}$ of Luria-Bertani broth in a Certomat BS-T incubation shaker (Sartorius Stedim Biotech, Aubagne, France) at $37^{\circ} \mathrm{C}$ and $150 \mathrm{rpm}$ until the culture reached an $\mathrm{OD}_{600}$ of 1.0 (Spekol UV VIS 3.02, Analytik Jena, Jena, Germany) corresponding to $10^{9}$ colony-forming units per $\mathrm{mL}$. The overnight cultures were diluted to $10^{8}$ colonyforming units per $\mathrm{mL}$ using sterile Luria-Bertani broth.

The antimicrobial activity of free streptomycin and the synthesized streptomycin nanocomposite was evaluated against MRSA using the agar diffusion (disk and cup) method as reported elsewhere. ${ }^{16}$ Briefly, $20 \mathrm{~mL}$ of liquid Mueller Hinton agar ( $\mathrm{pH} 7.3 \pm 0.2$ at $25^{\circ} \mathrm{C}$ ) was poured onto disposable sterilized Petri dishes and allowed to solidify. The surface of the solidified agar plates were allowed to dry in an incubator prior to streaking of microorganisms onto the surface of the agar plates. Next, $100 \mu \mathrm{L}$ of the microbial culture suspension in broth containing approximately $10^{6}$ colony-forming units per $\mathrm{mL}$ as measured spectrophotometrically was streaked over the dried surface of the agar plate, spread uniformly using sterilized glass rods, and allowed to dry before applying the loaded disks. The Strep-CS-MNP was suspended in sterilized distilled water, and blank sterilized Whatman
No 1 filter paper disks were loaded with the suspension. The loaded disks were applied carefully onto the surface of the seeded agar plates using sterile forceps. In addition, two wells were made in the agar using a sterilized cork borer and the two wells were filled with the nanoparticle suspensions and the control, respectively. The experiment was carried out in triplicate and the diameters of the zones of inhibition were measured after 24 hours of incubation at $37^{\circ} \mathrm{C}$. Free streptomycin was used as a control.

\section{Results and discussion X-ray diffraction}

Figure $1 \mathrm{~A}-\mathrm{C}$ shows the X-ray diffraction patterns for the magnetic nanoparticles, CS-MNP, and Strep-CS-MNP. The six characteristic peaks seen at $30.2^{\circ}(220), 35.5^{\circ}(311)$, $43.2^{\circ}(400), 53.5^{\circ}(422), 57.2^{\circ}(511)$, and $62.7^{\circ}$ (440) correspond to the iron oxide spinel structure (magnetite- $\mathrm{Fe}_{3} \mathrm{O}_{4}$ ) (JCPDS card No.19-0629), indicating that the magnetic nanoparticles, CS-MNP, and Strep-CS-MNP did not contain

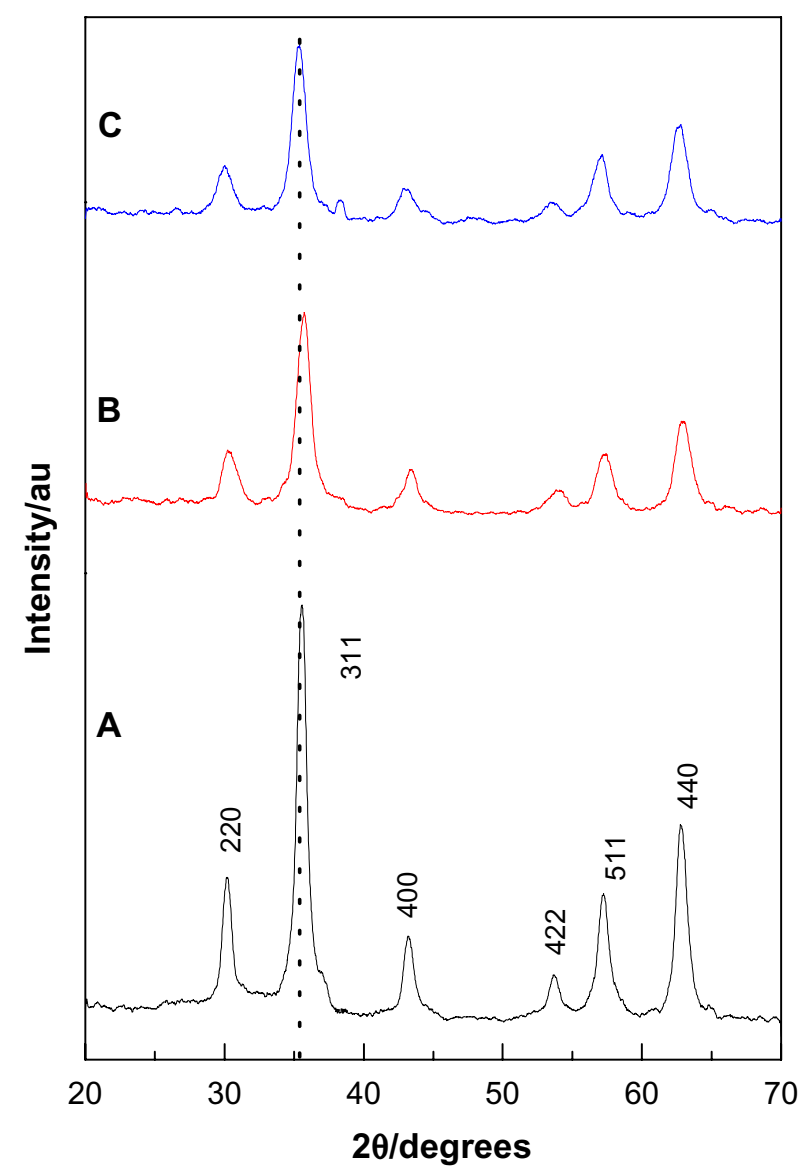

Figure I Powder X-ray diffraction patterns of magnetic nanoparticles (A), chitosanmagnetic nanoparticles (B), and streptomycin-loaded chitosan-magnetic nanocomposite (C). Abbreviation: au, arbitrary unit. 
any iron products such as hematite $\left(\alpha-\mathrm{Fe}_{2} \mathrm{O}_{3}\right)$, goethite, or iron hydroxides.

The average particle size was calculated using the DebyeScherrer formula, as shown in equation (1):

$$
\mathrm{D}=\frac{\mathrm{k} \lambda}{\beta \cos \theta}
$$

where $\mathrm{D}$ is the mean grain size, $\mathrm{k}$ is the Scherrer constant $(0.89), \lambda$ is the wavelength of $X$-ray diffraction $(0.15418 \mathrm{~nm})$, $\theta$ is the Bragg diffraction angle in degrees, and $\beta$ is the full width at half maximum intensity in radians. The diffraction peak corresponding to the lattice plane (311) at $2 \theta=35.4^{\circ}$ was used for calculation because this peak is well resolved and does not show any interferences. By substituting the full width at half maximum of the main peak (311), average particle sizes were calculated as $40 \mathrm{~nm}, 24 \mathrm{~nm}$, and $16 \mathrm{~nm}$ for the magnetic nanoparticles, CS-MNP, and Strep-CS-MNP, respectively.

\section{Infrared spectroscopy}

Figure 2A-D shows FTIR spectra for the magnetic nanoparticles, CS-MNP, Strep-CS-MNP, and free streptomycin, respectively. In Figure $2 \mathrm{~A}$, the magnetic nanoparticles show an absorption peak at $536 \mathrm{~cm}^{-1}$ which is due to $\mathrm{Fe}-\mathrm{O}$

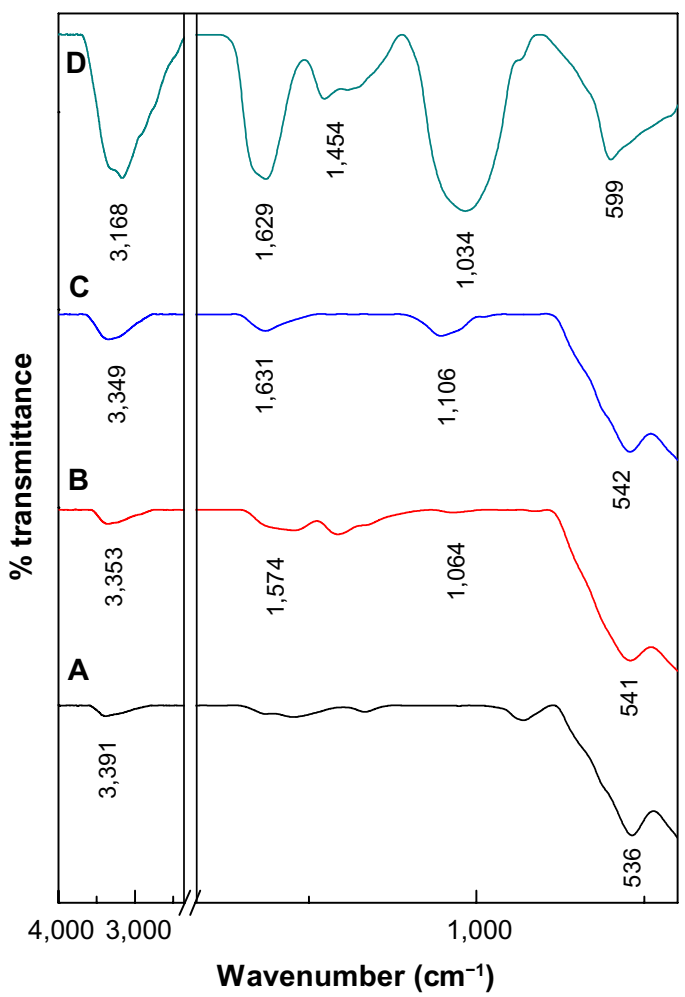

Figure 2 Fourier transform infrared spectra of magnetic nanoparticles (A), chitosan-magnetic nanoparticles (B), streptomycin-loaded chitosan-magnetic nanoparticles (C), and free streptomycin (D). stretching in $\mathrm{Fe}_{3} \mathrm{O}_{4}$. However, the CS-MNP and Strep-CSMNP samples show characteristic Fe-O peaks at 541 and $542 \mathrm{~cm}^{-1}$, respectively, confirming the presence of magnetite nanoparticles in both samples.

Comparing the spectrum of $\mathrm{CS}-\mathrm{Fe}_{3} \mathrm{O}_{4}$ (Figure 2B) with the spectrum of the $\mathrm{Fe}_{3} \mathrm{O}_{4}$ nanoparticles (Figure 2A), two characteristic peaks of chitosan appeared at $1,574 \mathrm{~cm}^{-1}$ and $1,064 \mathrm{~cm}^{-1}$, that are due to $\mathrm{NH}_{3}^{+17}$ and glycosidic bond stretching vibrations, ${ }^{18,19}$ respectively. These bands confirm coating of the magnetic nanoparticle with the chitosan polymer. The streptomycin molecule showed absorption bands at 1,629, 1,454 , and $1,034 \mathrm{~cm}^{-1}$ (Figure 2D). These bands are present in the spectra of Strep-CS-MNP nanocomposite with a slight shift, showing that the drug was incorporated into the nanocomposite (Figure 2C).

Figure 3 shows the interaction between streptomycin, chitosan, and magnetic nanoparticles in the Strep-CS-MNP nanocomposite. Using FTIR data, the chitosan polymer and the magnetic nanoparticles interacted via glycosidic bonds (MNP-O-CS). Dissolving the chitosan in acetic acid enabled a protonated $\mathrm{NH}_{2}$ group to form $\mathrm{NH}_{3}^{+}$. Therefore, streptomycin with $-\mathrm{OH}$ or $-\mathrm{NH}_{2}$ groups bound with chitosan via hydrogen bonds.

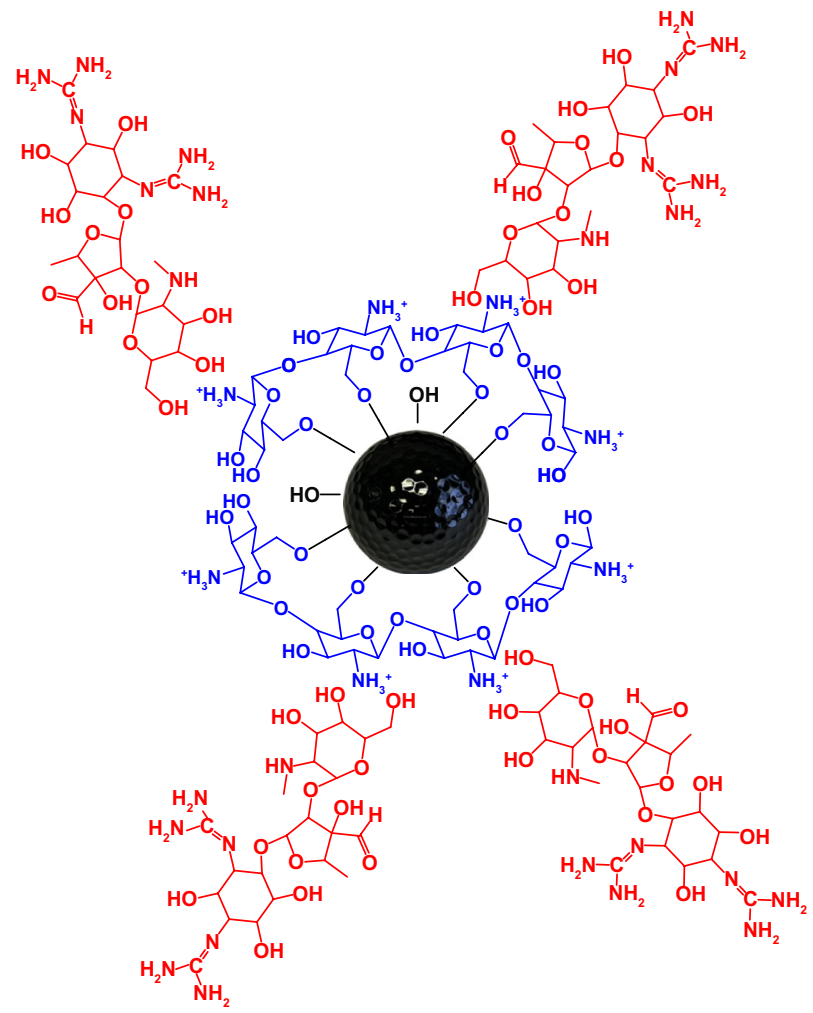

Figure 3 Schematic representation of the interaction between streptomycin, chitosan, and magnetic iron oxide in streptomycin-loaded chitosan-magnetic nanocomposite. 


\section{Thermogravimetric analysis}

Figure 4A-C shows the thermogravimetric analysis results for the magnetic nanoparticles, CS-MNP, and Strep-CSMNP nanocomposites, respectively. This analysis provides quantitative information about the components of CS-MNP and Strep-CS-MNP. The thermogravimetric analysis curve (Figure 4A) shows that the weight loss from the magnetic nanoparticles in the temperature range of $30^{\circ} \mathrm{C}-850^{\circ} \mathrm{C}$ is about $5.8 \%$. This weight loss was due to removal of absorbed water in the sample as well as removal of surface hydroxyl groups. ${ }^{20-22}$ The thermogravimetric analysis curve for CSMNP (Figure 4B) shows a total weight loss of $7.7 \%$. The increasing weight loss of the CS-MNP compared with that for the magnetic nanoparticles indicate binding of chitosan to the magnetic nanoparticles, with a $2.0 \%$ chitosan content.

Figure $4 \mathrm{C}$ shows the thermogravimetric analysis curve for Strep-CS-MNP. Weight loss below $200^{\circ} \mathrm{C}$ was due to removal of physically and chemically absorbed water. Strep-CS-MNP began to decompose at about $200^{\circ} \mathrm{C}$, and the temperature of the final decomposition was around $800^{\circ} \mathrm{C}$ (Figure 4 inset), with a total weight loss of $12.2 \%$. The weight loss from CSMNP was less than that from Strep-CS-MNP, which confirmed loading of streptomycin onto the CS-MNP surface.

\section{Measurement of magnetic properties}

The magnetic properties of the magnetic nanoparticles and Strep-CS-MNP are shown in Figure 5A-B, respectively. The

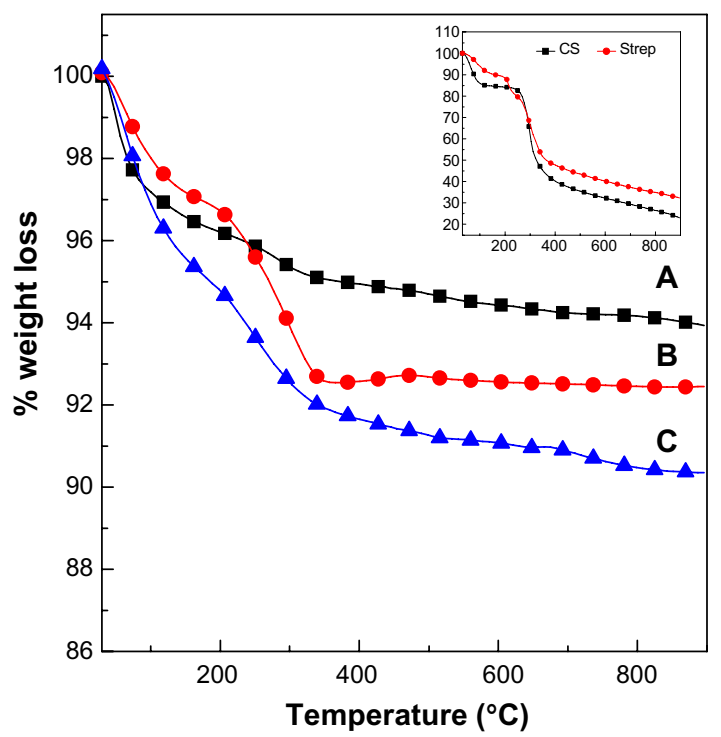

Figure 4 Thermogravimetric analysis curves of magnetic nanoparticles (A), chitosan-magnetic nanoparticles (B), and streptomycin-loaded chitosan-magnetic nanoparticles (C). The inset shows the thermogravimetric analysis curves for pure chitosan and free streptomycin.

Abbreviations: CS, chitosan; Strep, streptomycin.

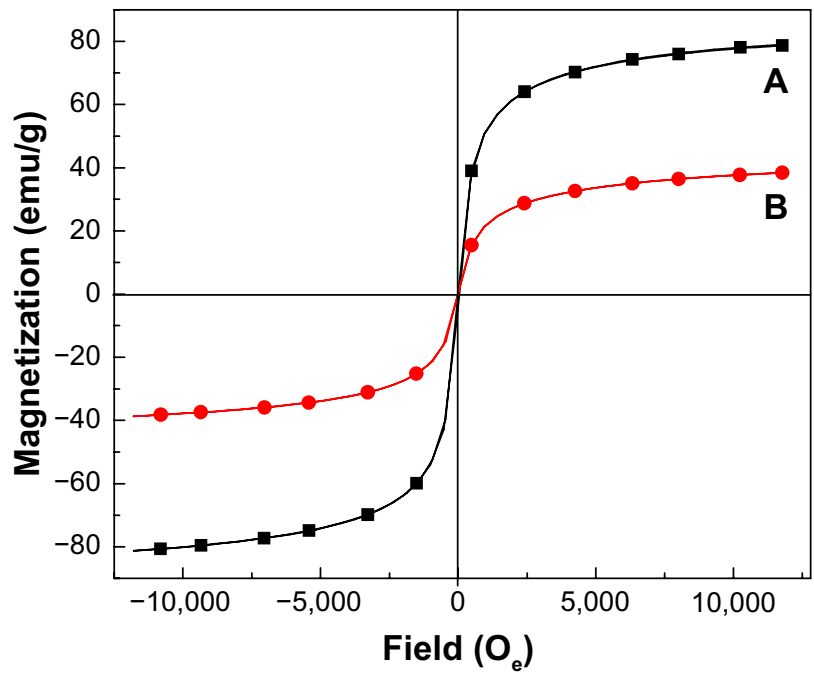

Figure 5 Magnetization curves of magnetic nanoparticles (A) and streptomycinloaded chitosan-magnetic nanoparticles $(\mathbf{B})$ recorded at room temperature. Abbreviation: $\mathrm{O}_{\mathrm{e}}$, Oersted.

study recorded magnetization $\left(\mathrm{M}_{\mathrm{s}}\right)$ values against an applied magnetic field $\left(\mathrm{O}_{\mathrm{e}}\right)$ at room temperature using a vibrating sample magnetometer. The curves exhibited negligible coercivity or remanent magnetization due to the superparamagnetic properties of the magnetic nanoparticles. ${ }^{23}$ This property is favorable for targeted drug delivery. ${ }^{24}$ The saturation magnetization $\left(\mathrm{M}_{\mathrm{s}}\right)$ of Strep-CS-MNP at $\pm 11,700 \mathrm{O}_{\mathrm{e}}$ was measured as $38.4 \mathrm{emu} / \mathrm{g}$, whereas the $M_{\mathrm{s}}$ value for the magnetic nanoparticle was $80.1 \mathrm{emu} / \mathrm{g}$. However, the $\mathrm{M}_{\mathrm{s}}$ for Strep-CS-MNP was less than that for the magnetic nanoparticle. The decrease in Ms for Strep-CS-MNP could be due to the polymer coating and the exchange of electrons between the surface of $\mathrm{Fe}$ atoms and the polymer, ${ }^{20,22,25}$ indicating that the magnetic nanoparticles were coated with the polymer.

\section{Scanning electron microscopy analysis}

Figure 6 shows the surface morphology of the MNP nanoparticles and the Strep-CS-MNP nanocomposite observed by scanning electron microscopy. Figure 6 shows that the MNP and the Strep-CS-MNP nanocomposite have strong agglomeration due to van der Waals forces between the particles. The degree of agglomeration was decreased in Strep-CS-MNP due to coating of the MNP nanoparticles by the chitosan polymer.

\section{In vitro release of streptomycin from Strep-CS-MNP}

The release profiles for streptomycin from the Strep-CSMNP nanocomposite using $0.01 \mathrm{M}$ phosphate-buffered saline and release of streptomycin from the physical mixture 

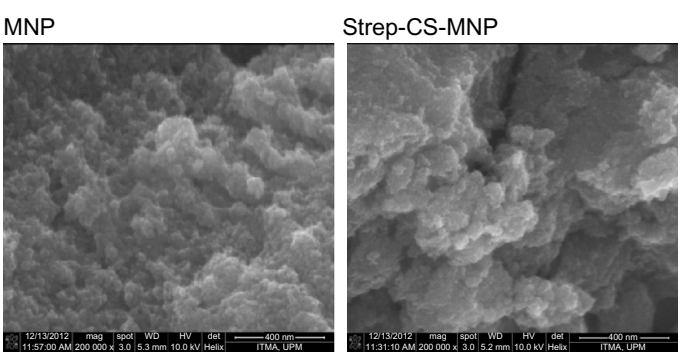

Figure 6 Scanning electron micrographs of MNP and Strep-CS-MNP at 200,000 magnification.

Notes: $x$ after 200,000 meaning 200,000 X

Abbreviations: MNP, magnetic nanoparticles; Strep-CS-MNP, streptomycin-loaded chitosan-magnetic nanoparticles.

of streptomycin, chitosan and magnetic nanoparticles are shown in Figure 7. As can be seen from the inset of this figure, the free streptomycin (physical mixture) was released rapidly into phosphate-buffered saline, with complete release taking place within 20 minutes. The release rate of streptomycin from the nanocomposite is obviously lower than that of the free mixture, indicating that the nanocomposite is a potential controlled-release drug delivery system. It is worth noting that the rapid release during the first 20 minutes is due to the burst effect. A slower release was observed from 25 to 350 minutes, and the amount of streptomycin released from the nanocomposite at 350 minutes was $100 \%$.

\section{Release kinetics of streptomycin from Strep-CS-MNP}

In order to obtain more information on the release behavior of streptomycin from the Strep-CS-MNP nanocomposite, a pseudo-first order model (Equation 2), ${ }^{26}$

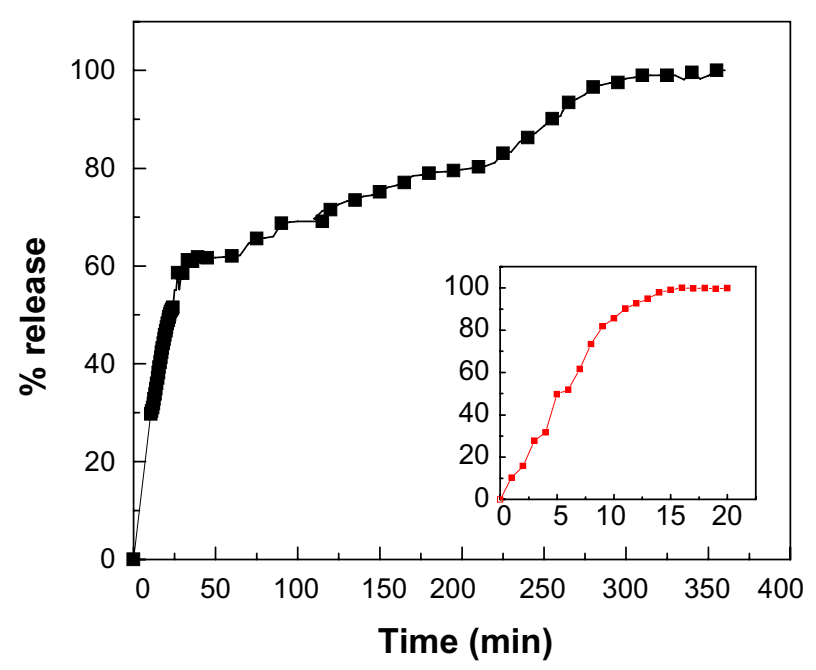

Figure 7 Release profiles for streptomycin from the streptomycin-loaded chitosanmagnetic nanoparticle nanocomposites at $\mathrm{pH}$ 7.4. Inset shows the release profiles of streptomycin from the physical mixture. a pseudo-second order model (Equation 3), ${ }^{27}$ the Higuchi model (Equation 4), ${ }^{28}$ the Hixson-Crowell model (Equation 5), ${ }^{28}$ and the Korsmeyer-Peppas model (Equation 6$)^{28}$ were chosen as follows:

$$
\begin{gathered}
\ln \left(\mathrm{q}_{\mathrm{e}}-\mathrm{q}_{\mathrm{t}}\right)=\ln \mathrm{q}_{\mathrm{e}}-\mathrm{kt} \\
\mathrm{t} / \mathrm{q}_{\mathrm{t}}=1 / \mathrm{k} \mathrm{q}_{\mathrm{e}}^{2}+\mathrm{t} / \mathrm{q}_{\mathrm{e}} \\
\mathrm{q}_{\mathrm{t}}=\mathrm{K} \sqrt{\mathrm{t}} \\
\sqrt[3]{\mathrm{M}_{\mathrm{o}}}-\sqrt[3]{\mathrm{M}_{\mathrm{t}}}=\mathrm{Kt} \\
\frac{\mathrm{q}_{\mathrm{t}}}{\mathrm{q}_{\infty}}=\mathrm{Kt}^{\mathrm{n}}
\end{gathered}
$$

where $\mathrm{q}_{\mathrm{e}}$ and $\mathrm{q}_{\mathrm{t}}$ are the equilibrium release amounts and the release amounts at any time $(t)$, respectively, $M_{o}$ and $M_{t}$ is the initial amount and the amount of the drug in the nanocomposite at time $t$, respectively.

Based on the five models, the fitted results of the streptomycin release profiles are given in Figure 8 and Table 1. It can be seen that the pseudo-second order model can be better fitted to the data for streptomycin release behavior than the other models. Figure $8 \mathrm{~B}$ shows the plots of $\mathrm{t} / \mathrm{q}_{\mathrm{t}}$ versus $\mathrm{t}$ for the release of streptomycin. The correlation coefficient $\left(R^{2}\right)$ value was 0.9863 , compared with $0.8772,0.9280,0.9394$, and 0.9235 for the pseudo-first order model, the Higuchi model, the Hixson-Crowell model, and the Korsmeyer-Peppas model, respectively.

\section{In vitro antibacterial activity of Strep-CS-MNP}

In the present study, the antibacterial activity of the assynthesized Strep-CS-MNP was determined against a strain of MRSA using the agar diffusion method as described previously. Strep-CS-MNP showed antimicrobial activity against MRSA, as indicated by the clear inhibition zone shown in Figure 9. The diameters of the inhibition zone for Strep-CSMNP were $17 \mathrm{~mm}$ for $\mathrm{B}$ and $21 \mathrm{~mm}$ for $\mathrm{C}$ as compared to $32 \mathrm{~mm}$ for free streptomycin (A), which indicates that the as-synthesized Strep-CS-MNP showed enhanced antibacterial activity.

As a field of research with promising and vast applications in pharmaceutical and biomedical development, nanoantimicrobial agents are being developed based on several metal and metal oxide nanoparticles, including silver, gold, zinc, and copper, ${ }^{2,22,29-31}$ despite concerns about the toxicity of their metal content, such as accumulation in the body and other cytotoxic and genotoxic effects as compared with their antimicrobial benefits. ${ }^{32,33}$ In addition to 

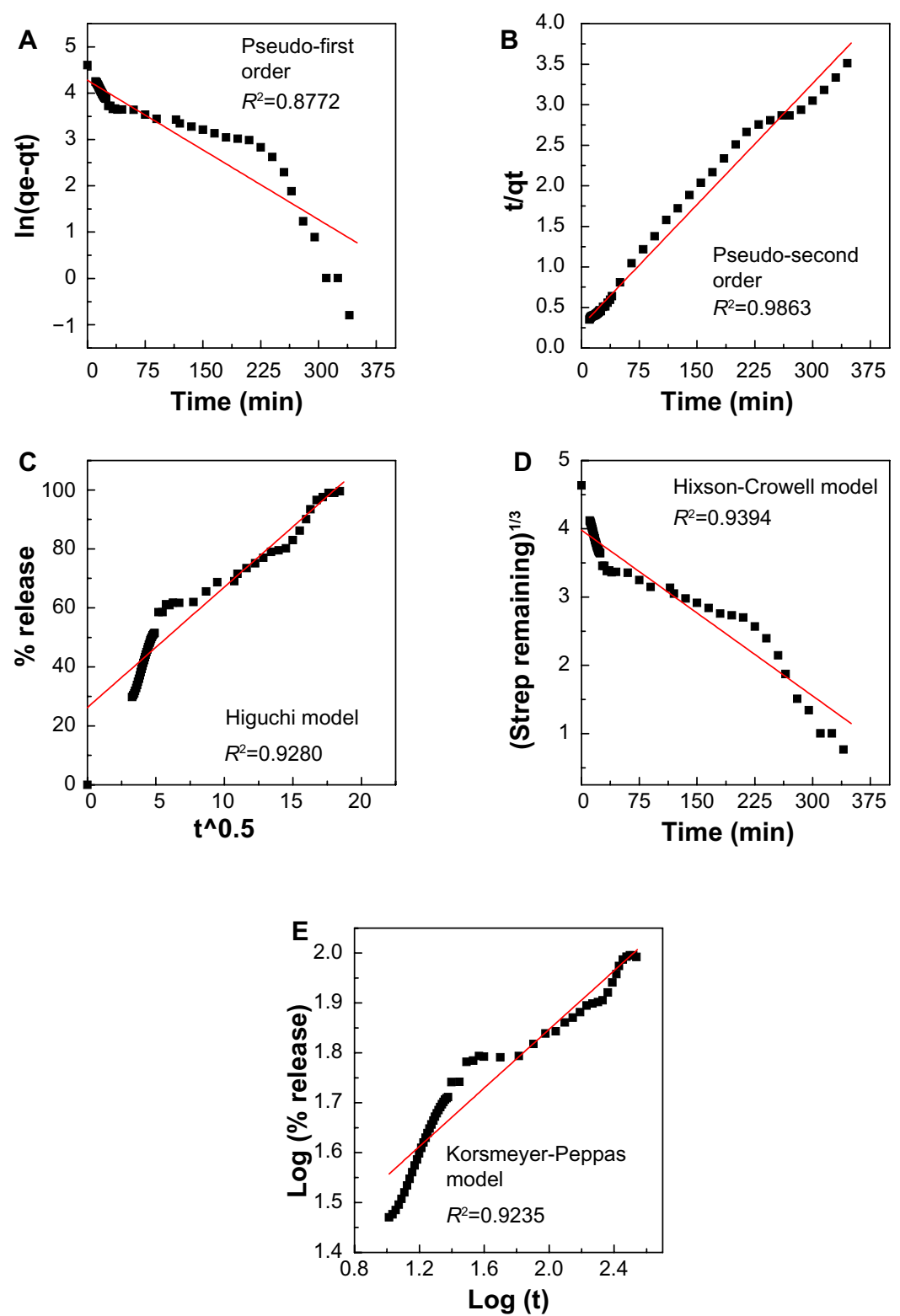

Figure 8 Fitting of data for streptomycin release from the streptomycin-loaded chitosan-magnetic nanoparticle nanocomposite for different kinetic models at pH 7.4.

the research efforts being devoted to develop chemically modified new generations and more stable derivatives of aminoglycosides in order to improve their clinical advantages and to overcome the escalating antimicrobial resistance, nanoparticle-based antibiotics, commonly known as nanoantibiotics or nanobiotics (the terms are used interchangeably) were very recently introduced and represent a major breakthrough in nanomedicine, ${ }^{34,35}$ although the literature thus far contains very few reports on antibiotic-loaded nanoparticles. ${ }^{36-38}$

Table I Correlation coefficient $\left(R^{2}\right)$ obtained by fitting streptomycin release data from Strep-CS-MNP nanocomposites into phosphatebuffered saline at $\mathrm{pH} 7.4$

\begin{tabular}{lllllll}
\hline Sample & $\begin{array}{l}\text { Saturation } \\
\text { release (\%) }\end{array}$ & Pseudo-first order & Pseudo-second order & $\begin{array}{l}\text { Higuchi } \\
\text { model }\end{array}$ & $\begin{array}{l}\text { Hixson-Crowell } \\
\text { model }\end{array}$ & $\begin{array}{l}\text { Korsmeyer-Peppas } \\
\text { model }\end{array}$ \\
\hline Strep-CS-MNP & 100 & 0.8772 & 0.9863 & 0.9280 & 0.9394 \\
\hline
\end{tabular}

Abbreviation: Strep-CS-MNP, streptomycin-loaded chitosan-magnetic nanoparticles. 


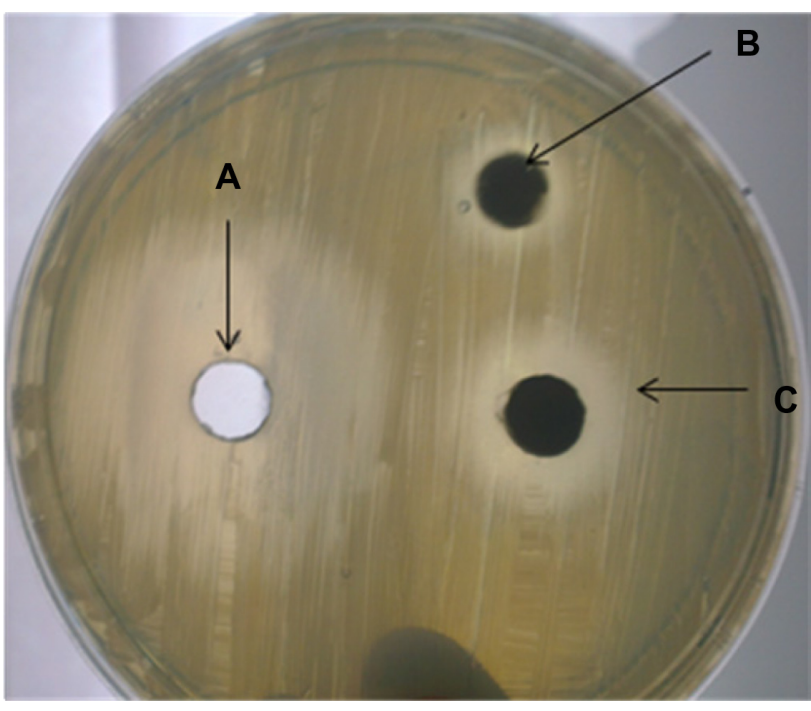

Figure 9 Antimicrobial activity of streptomycin-loaded chitosan-magnetic nanoparticle nanocomposites using agar diffusion method. Zones of inhibition of free streptomycin (A) streptomycin-loaded chitosan-magnetic nanoparticle nanocomposites (B) disk-loaded nanoparticles and (C) water-suspended nanoparticles in a cup against a bacterial strain of methicillin-resistant Staphylococcus aureus were measured as determined using the agar diffusion method.

\section{Conclusion and future perspectives}

Magnetic iron oxide nanoparticles were prepared with chitosan by incorporation methods, and characterized using FTIR spectroscopy, X-ray diffraction, thermogravimetric analysis, and vibrating sample magnetometry. Streptomycin was incorporated into the nanoparticles. Vibrating sample magnetometry studies showed the supermagnetic properties of the magnetic nanoparticles. The streptomycin loading was 4.2\%. Drug release was also studied, and the total release equilibrium of streptomycin from Strep -CS-MNP was 100\% in 350 minutes. The drug release profiles showed initially rapid release, which became slower as time progressed. The best fitting of mathematical model was the pseudo-second order model.

To the authors' knowledge, this is the first report on the synthesis of nanoparticles loaded with streptomycin as a prototype aminoglycoside antibiotic and would pave the way for further promising research. Further investigation of the activity of the Strep-CS-MNP nanocomposites against other microorganisms including Mycobacterium tuberculosis and in vivo studies to elucidate drug delivery, stability against bacterial resistance, and the toxicity and side effects of Strep -CS-MNP would provide opportunities for future advances in nanobiotics and nanomedicine in the clinical setting.

The widespread emergence of microbial resistance to several classes of antimicrobial agents raises more concerns in health care and public health, perhaps heralding a resurgence of bacterial outbreaks caused by microorganisms with the potential to cause fatal infections in humans and animals. Antimicrobialresistant microorganisms require more extensive chemotherapy, involving drug therapy over an extended period, which may often end unsuccessfully, and is more expensive (billions of dollars) than treatment for antimicrobial-susceptible microrganisms. The pros and cons of the potential applications of nanoantibiotics as potential treatment options in a post-antibiotic era to control infectious diseases and offset the overwhelming microbial resistance should be fully addressed and evaluated. The clinical ineffectiveness and effectiveness of several commonly used antibiotics (such as $\beta$-lactams, aminoglycosides, and macrolides, as well as antifungal antibiotics such as polyenes) mandate the expedited requirement for improvements in drug design, discovery, and delivery. In addition, further studies on the antimicrobial spectra of novel Strep-CS-MNP nanoparticles against $M$. tuberculosis and related microorganisms could offer new antimycobacterial and antimicrobial alternatives in the treatment of infectious diseases.

Development of new antimicrobial agents usually takes a few years to reach clinical application; however, nanomedicine provides a rapid tool to enhance and restore the antimicrobial activity of old and current antibiotics that are affected by the multiple drug resistance arsenal of pathogens. Future research in the nanoantibiotic field should be expanded and devoted to address different aspects regarding delivery, safety, and possible toxicity of such novel nanoscale antimicrobial agents.

\section{Acknowledgments}

The authors would like to thank the Ministry of Higher Education of Malaysia under grant ERGS/1/11/STG/UPM/01/18 vote (5527050) and the Universiti Putra Malaysia for the postdoctoral support of Samer H Hussein-Al-Ali.

\section{Disclosure}

The authors report no conflicts of interest in this work.

\section{References}

1. Gupta AK, Wells S. Surface-modified superparamagnetic nanoparticles for drug delivery: preparation, characterization, and cytotoxicity studies. NanoBioscience. 2004;3:66-73.

2. Tran N, Webster TJ. Magnetic nanoparticles: biomedical applications and challenges. J Mater Chem. 2010;20:8760-8767.

3. Sun S, Zeng H. Size-controlled synthesis of magnetite nanoparticles. J Am Chem Soc. 2002;124:8204-8205.

4. Jones N, Ray B, Ranjit KT, Manna AC. Antibacterial activity of ZnO nanoparticle suspensions on a broad spectrum of microorganisms. FEMS Microbiol Lett. 2008;279:71-76.

5. Rabea EI, Badawy MET, Stevens CV, Smagghe G, Steurbaut W. Chitosan as antimicrobial agent: applications and mode of action. Biomacromolecules. 2013;4:1457-1465.

6. Raafat D, Von Bargen K, Haas A, Sahl H-G. Insights into the mode of action of chitosan as an antibacterial compound. Appl Environ Microbiol. 2008;74:3764-3773. 
7. Eckhardt S, Brunetto PS, Gagnon J, Priebe M, Giese B, Fromm KM. Nanobio silver: its interactions with peptides and bacteria, and its uses in medicine. Chem Rev. 2013:4708-4754.

8. Mahmoudi M, Serpooshan V. Silver-coated engineered magnetic nanoparticles are promising for the success in the fight against antibacterial resistance threat. ACS Nano. 2012;6:2656-2664.

9. Schatz A, Waksman SA. Effect of streptomycin and other antibiotic substances upon Mycobacterium tuberculosis and related organisms. In: Proceedings of the Society for Experimental Biology and Medicine Society for Experimental Biology and Medicine. New York, NY: Royal Society of Medicine; 1944.

10. Murray JF. A century of tuberculosis. Am J Respir Crit Care Med. 2004;169:1181-1186.

11. Schatz A, Bugle E, Waksman SA. Streptomycin, a substance exhibiting antibiotic activity against Gram-positive and Gram-negative bacteria. In: Proceedings of the Society for Experimental Biology and Medicine Society for Experimental Biology and Medicine. New York, NY: Royal Society of Medicine; 1944.

12. Ramirez MS, Nikolaidis N, Tolmasky ME. Rise and dissemination of aminoglycoside resistance: the aac $\left(6^{\prime}\right)$-Ib paradigm. Front Microbiol. 2013;4:121.

13. Becker B, Cooper MA. Aminoglycoside antibiotics in the 21 st century. ACS Chem Biol. 2012;8:105-115.

14. Edson RS, Terrell CL. The aminoglycosides. Mayo Clin Proc 1991;66:1158-1164.

15. Kuznetsov AA, Filippov VI, Kuznetsov OA, Gerlivanov VG, Dobrinsky EK, Malashin SI. New ferro-carbon adsorbents for magnetically guided transport of anti-cancer drugs. J Magn Magn Mater. 1999;194:22-30

16. Andrews JM. BSAC standardized disc susceptibility testing method. J Antimicrob Chemother. 2001;48 Suppl 1:43-57.

17. Silva SML, Braga CRC, Fook MVL, Raposo CMO, Carvalho LH, Canedo EL. Application of infrared spectroscopy to analysis of chitosan/clay nanocomposites. In: Theophanides T, editor. Infrared Spectroscopy - Materials Science, Engineering and Technology; 2012. Available from: http:/www.intechopen.com/books/infrared-spectroscopy-materials-science-engineering-andtechnology/application-ofinfrared-spectroscopy-to-analysis-of-chitosan-clay-nanocomposites. Accessed October 3, 2013.

18. Qu JB, Shao HH, Jing GL, Huang F. PEG-chitosan-coated iron oxide nanoparticles with high saturated magnetization as carriers of 10-hydroxycamptothecin: preparation, characterization and cytotoxicity studies. Colloids Surf B Biointerfaces. 2013;102:37-44.

19. Inbaraj BS, Tsai T-Y, Chen B-H. Synthesis, characterization and antibacterial activity of superparamagnetic nanoparticles modified with glycol chitosan. Sci Tech Adv Mater. 2012;13:015002.

20. Shan Z, Yang W-S, Zhang X, Huang Q-M, Ye H. Preparation and characterization of carboxyl-group functionalized superparamagnetic nanoparticles and the potential for bio-applications. J Braz Chem Soc. 2007; 18:1329-1335.

21. Inbaraj BS, Kao TH, Tsai TY, Chiu CP, Kumar R, Chen BH. The synthesis and characterization of poly (Y-glutamic acid)-coated magnetite nanoparticles and their effects on antibacterial activity and cytotoxicity. Nanotechnology. 2011;22:075101.
22. Chaloupka K, Malam Y, Seifalian AM. Nanosilver as a new generation of nanoproduct in biomedical applications. Trends Biotechnol. 2010;28:580-588.

23. Daou TJ, Pourroy G, Begin-Colin S, et al. Hydrothermal synthesis of monodisperse magnetite nanoparticles. Chem Mater. 2006;18: 4399-4404.

24. Peng X-H, Qian X, Mao H, et al. Targeted magnetic iron oxide nanoparticles for tumor imaging and therapy. Int J Nanomedicine. 2008; 3:311-321.

25. Yu S, Chow GM. Carboxyl group $\left(-\mathrm{CO}_{2} \mathrm{H}\right)$ functionalized ferrimagnetic iron oxide nanoparticles for potential bio-applications. J Mater Chem. 2004;14:2781-2786.

26. Dong L, Yan L, Hou W-G, Liu S-J. Synthesis and release behavior of composites of camptothecin and layered double hydroxide. J Solid State Chem. 2010;183:1811-1816.

27. Ho Y-S, Ofomaja AE. Pseudo-second-order model for lead ion sorption from aqueous solutions onto palm kernel fiber. $J$ Hazard Mater. 2006;129:137-142.

28. Sakore S, Chakraborty B. Formulation and evaluation of enalapril maleate sustained release matrix tablets. Int J Pharm. 2013;4:21-26.

29. Seil JT, Webster TJ. Antimicrobial applications of nanotechnology: methods and literature. Int J Nanomedicine. 2012;7:2767.

30. Matthews L, Kanwar RK, Zhou S, Punj V, Kanwar JR. Applications of nanomedicine in antibacterial medical therapeutics and diagnostics. The Open Tropical Medicine Journal. 2010;3:1-9.

31. Hajipour MJ, Fromm KM, Akbarashkarran A, et al. Antibacterial properties of nanoparticles. Trends Biotechnol. 2012;30:497-554.

32. Hackenberg S, Scherzed A, Kessler M, et al. Silver nanoparticles: evaluation of DNA damage, toxicity and functional impairment in human mesenchymal stem cells. Toxicol Lett. 2011;201:27-33.

33. Arora S, Rajwade JM, Paknikar KM. Nanotoxicology and in vitro studies: the need of the hour. Toxicol Appl Pharmacol. 2012;258:151-165.

34. Huh AJ, Kwon YJ. "Nanoantibiotics": a new paradigm for treating infectious diseases using nanomaterials in the antibiotics resistant era. J Control Release. 2011;156:128-145.

35. Yacoby I, Benhar I. Antibacterial nanomedicine. Nanomedicine. 2008;3:329-341.

36. Abeylath SC, Turos E, Dickey S, Lim DV. Glyconanobiotics: novel carbohydrated nanoparticle antibiotics for MRSA and Bacillus anthracis. Bioorg Med Chem. 2008;16:2412-2418.

37. Garay-Jimenez JC, Gergeres D, Young A, Lim DV, Turos E. Physical properties and biological activity of poly (butyl acrylate-styrene) nanoparticle emulsions prepared with conventional and polymerizable surfactants. Nanomedicine. 2009;5:443-451.

38. Turos E, Reddy G, Greenhalgh K, et al. Penicillin-bound polyacrylate nanoparticles: restoring the activity of $\beta$-lactam antibiotics against MRSA. Bioorg Med Chem Lett. 2007;17:3468-3472.
International Journal of Nanomedicine

\section{Publish your work in this journal}

The International Journal of Nanomedicine is an international, peerreviewed journal focusing on the application of nanotechnology in diagnostics, therapeutics, and drug delivery systems throughou the biomedical field. This journal is indexed on PubMed Central,

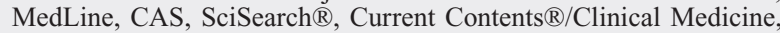

\section{Dovepress}

Journal Citation Reports/Science Edition, EMBase, Scopus and the Elsevier Bibliographic databases. The manuscript management system is completely online and includes a very quick and fair peer-review system, which is all easy to use. Visit http://www.dovepress.com/ testimonials.php to read real quotes from published authors. 